\title{
Examination of Annular-Electrode Spark Discharges in Flowing Oxygen - An Overview
}

\author{
Darren C. Tinker ${ }^{1}$, \\ Vanderbilt University, Nashville, TN, 37212 \\ And \\ Robin J. Osborne ${ }^{2}$ \\ ERC, Inc., Jacobs Space Exploration Group, Huntsville, AL 35812 \\ And \\ Robert W. Pitz ${ }^{3}$, \\ Vanderbilt University, Nashville, TN, 37212
}

\begin{abstract}
A parametric study of annular spark gaps, pressures, and spark discharges in flowing oxygen gas was performed with a Champion spark exciter. The range of the pressure-distance product for the experiment is from approximately 50 torr-cm to 2500 torr-cm. Measurements of breakdown voltage qualitatively trend with Paschen's curve. Spark duration remained constant until the pressure-distance product exceeded 200 torr-cm, and then steadily increased. The mean spark energy increases linearly with the pressure-distance on a log-log plot indicating that a definite power relationship exists. The distribution of sparks at low energies and low pressures is not Gaussian and has no dominant peaks. Moderate and high spark energies are bimodal, with the dominant mode near $80 \mathrm{~mJ}$. As pressure increases, dominant and secondary modes approach the same probability.
\end{abstract}

\section{Introduction}

In liquid propellant rocket engines, spark igniters are often used indirectly to light preburners, gas generators, and main chambers [1]. Attraction for spark igniters is strongly influenced by their ability for repeatable engine starts and high reliability. In the case of spark igniters, however, ignition is reliant upon an ignitable mixture passing near the spark tip very early in the engine start transient, prior to pressure quenching of the spark. While direct ignition of rocket engine combustion chambers is possible and has been successfully implemented in engines such as RL10 , the development time can be significant since ignition requires precise and repeatable control of the propellant mixture ratio within the very small volume and short duration of the spark plasma. Generally, the preferred method of implementing spark igniters within rocket engines

${ }^{1}$ Graduate Student, VU Station B \#351592, 2301 Vanderbilt Place. Student Member.

${ }^{2}$ Senior Engineer, Mail Stop ER36, NASA Marshall Space Flight Center. Senior Member.

${ }^{3}$ Professor, VU Station B \#351592, 2301 Vanderbilt Place. Associate Fellow. 
AIAA Propulsion and Energy Forum and Exposition (AIAA P\&E 2018);

Duke Energy Convention Center, Cincinnati, OH, 9 - 11 July 2018

especially larger engines, is to design a smaller "augmented spark igniter" pre-chamber in which propellant injection and mixture ratio near the spark plasma can be controlled independent of the engine injector. The resultant combustion products within the small pre-chamber are directed into the larger engine chamber via a torch tube. An augmented spark igniter is advantageous because the output torch flame that is much larger and more energetic than a discrete train of small spark plasmas.

Even within the smaller volume of the augmented spark igniter pre-chamber, immediate and reliable ignition can still be a design challenge, especially with hydrocarbon-based fuels. To date, the only use of spark igniters in human-rated rocket engines has been with pure hydrogen, which has much broader flammability limits than hydrocarbon fuels, when combined with oxygen. In order to enhance the spark plasma within an augmented spark igniter, a fraction of the propellant (usually the oxidizer), may be injected so that it passes through the electrical arc of the spark igniter. In doing this, the spark plasma is pushed out further from the spark tip, where it is more likely that an ignitable mixture exists and cold wall quenching of the initial combustion kernel is less of a concern.

The objective of the research conducted in this study is to examine and better understand how the spark plasma is affected by the flow of oxidizer through the electrical spark. In the field of spark ignition for combustion devices, research has ranged from studies of electrical characteristics [2] [3] [4] to imaging of ignition kernels following the discharge [5] [6]. The majority of this literature focuses on pronged electrodes, which had input parameters and geometric shapes thoroughly varied [5] [7] [8]. Often, such work focuses on stagnant conditions as information for flowing gases will rely on specifics of an application.

\section{Experiment and Data Processing}

\section{A. Setup}

Schlieren imaging of the electrical discharge and subsequent product clouds were taken using the experimental setup shown in Fig. 1. The system consisted of two f/10 8 inch diameter parabolic mirrors spaced 72 inches apart with the light source slit and knife edge 7.5 inches from the centerline of the collimated light. The light source was a CREE XM-L2 LED supplied with 12V and 3A. A condenser array followed the LED module with two $50 \mathrm{~mm}$ diameter, $100 \mathrm{~mm}$ focal length achromats spaced for a 1:1 magnification, which was then cropped by a horizontal slit and iris aperture. A Phantom v310 high speed camera was used in conjunction with a Sigma aspherical 170-500 mm f5-6.3 lens, and provided a spatial resolution of 280 micron as determined by a 1951 USAF resolution chart. Electrical measurements were taken with a model 410 Pearson current monitor ( $50 \Omega$ termination, thus sensitivity lowered by factor of two), model P6015 Tektronix high voltage probe (1M $\Omega$ termination), and recorded by a Teledyne LeCroy WaveSurfer 44MXs-b oscilloscope. The high voltage probe was the triggering channel with an $800 \mathrm{~V}$ threshold. Time resolution between data points was $2 \mathrm{~ns}$ for a duration of $200 \mu \mathrm{s}$, and 240 triggered events were recorded per video. Results were integrated over time to provide mean results for electrical signals. Figure 2 shows a mean result of voltage and current vs. time for reference.

Mass flow was regulated by a Fox choke venturi with a 0.051 " diameter. Fluid properties were measured using Omega Type K open tip, ungrounded, 0.010" diameter wire thermocouples, and Omega PX309-500A5V pressure transducers. Measurements were recorded by a LabView cRIO9064. Sparks were generated from a capacitive Champion exciter powered by a Tektronix PWS4305 DC power supply. 
AIAA Propulsion and Energy Forum and Exposition (AIAA P\&E 2018);

Duke Energy Convention Center, Cincinnati, OH, 9 - 11 July 2018

Pure oxygen was used as the oxidizer with supply pressures and stainless steel spark gaps shown in Table 1. Note that spark gaps 5 and 7 were excluded from this study. The oxidizer was injected into a cavity upstream of the spark gap, then directed through an annulus formed by two electrodes. Sparks formed within the annulus and were extended outward by the flow. The excited gas is carried downstream by the bulk flow where it inevitably reached equilibrium.

Table 1 Spark gap electrode diameters, and supply pressures used in experiment

\begin{tabular}{c|c|c}
$\begin{array}{c}\text { Spark } \\
\text { Gap }\end{array}$ & $\begin{array}{c}\text { Outer Diameter } \\
\text { [in] }\end{array}$ & $\begin{array}{c}\text { Inner Diameter } \\
\text { [in] }\end{array}$ \\
\hline 1 & 0.0205 & 0.094 \\
\hline 2 & 0.0315 & 0.094 \\
\hline 3 & 0.0415 & 0.094 \\
\hline 4 & 0.0510 & 0.094 \\
\hline N/A & - & - \\
\hline 6 & 0.0715 & 0.094 \\
\hline N/A & - & - \\
\hline 8 & 0.0915 & 0.094
\end{tabular}

\begin{tabular}{c|c} 
Setting & $\begin{array}{c}\text { Supply Pressure } \\
\text { [psia] }\end{array}$ \\
\hline 1 & 20 \\
\hline 2 & 40 \\
\hline 3 & 65 \\
\hline 4 & 90 \\
\hline 5 & 115 \\
\hline 6 & 190 \\
\hline 7 & 265 \\
\hline 8 & 340 \\
\hline 9 & 415 \\
\hline 10 & 515
\end{tabular}

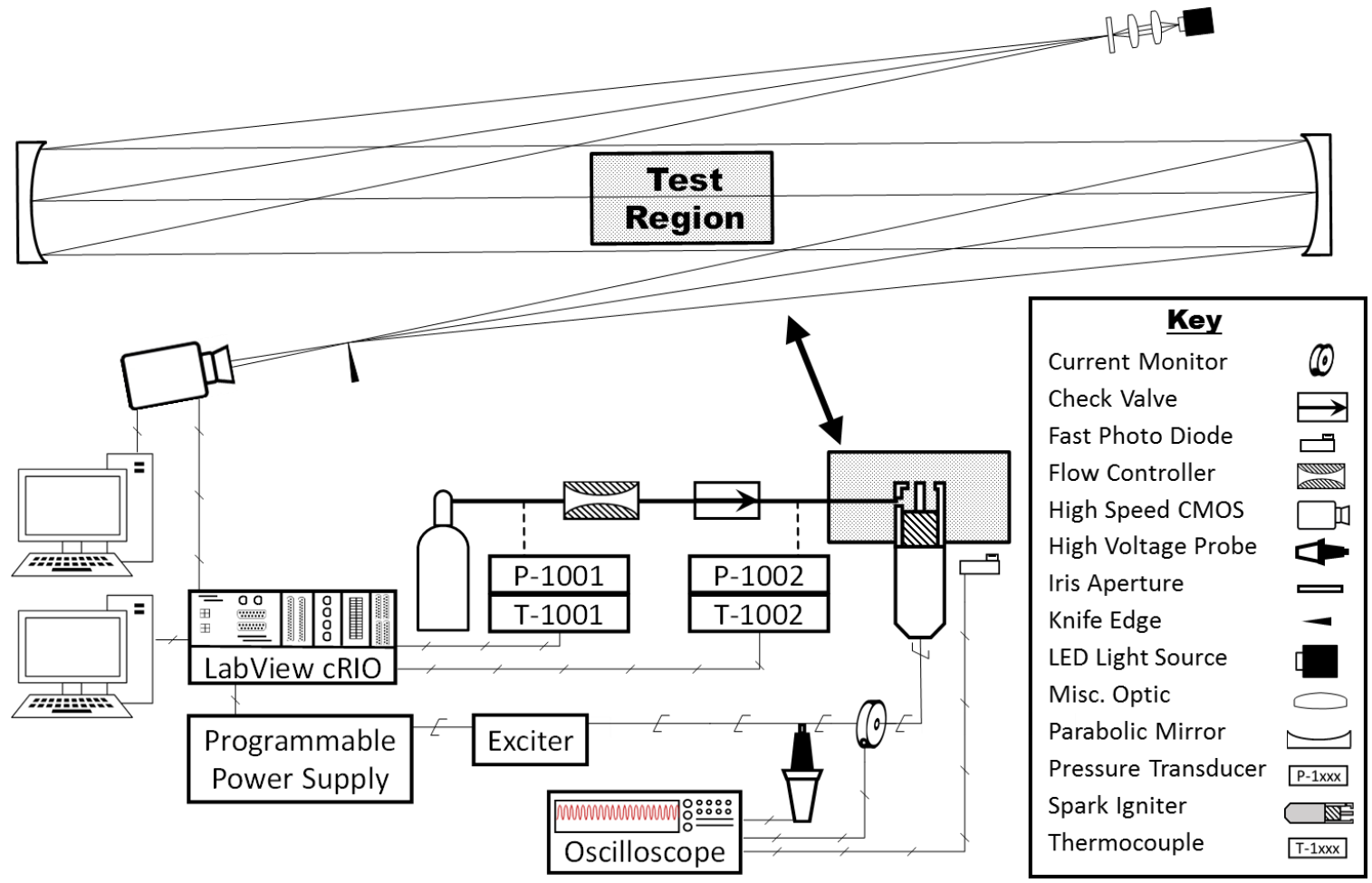

Fig. 1 Detailed schematic of experimental setup for Schlieren imaging and other common measurements 


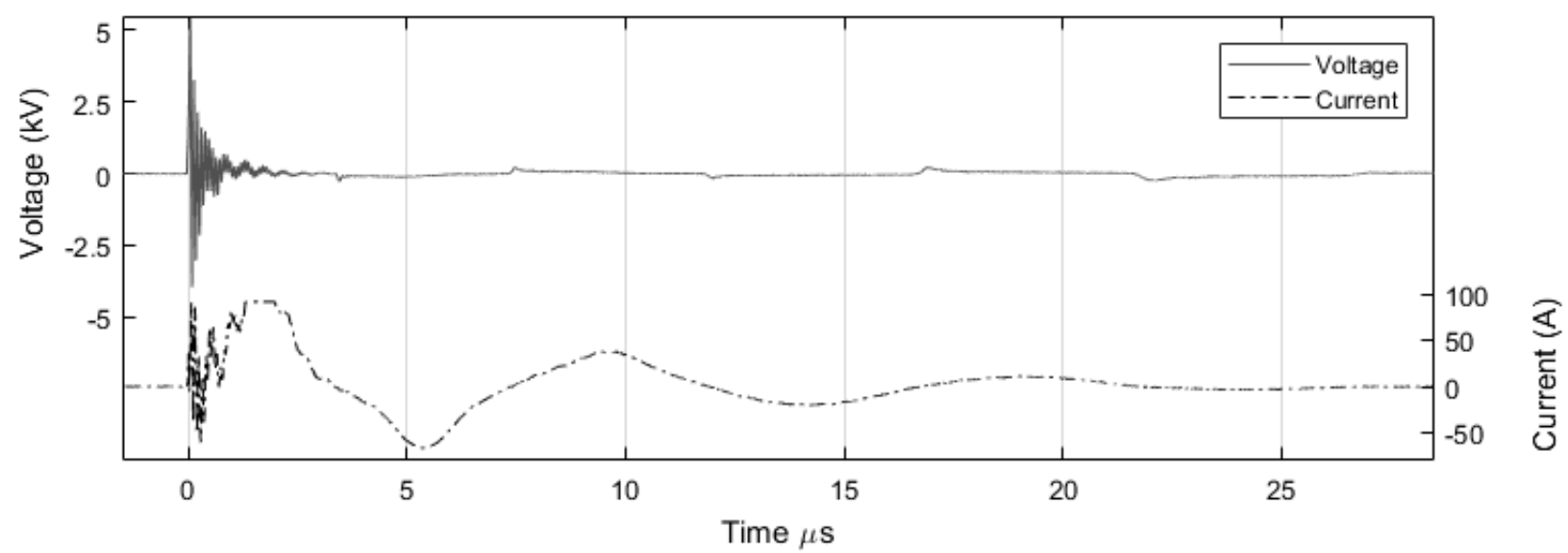

Fig. 2 Typical mean voltage and current shapes

\section{B. Schlieren Post Processing}

For reference, Fig. 3 shows a schematic of the spark igniter cap juxtaposed with a schlieren image. Gases enter the spark igniter gap from one side, fill the chamber then exit through the annulus. The gap cap is removable, and the means to change the diameter of the outer electrode. An O-ring sits in a channel between the gap cap and gap body to prevent gas from escaping, but is not shown in the schematic.

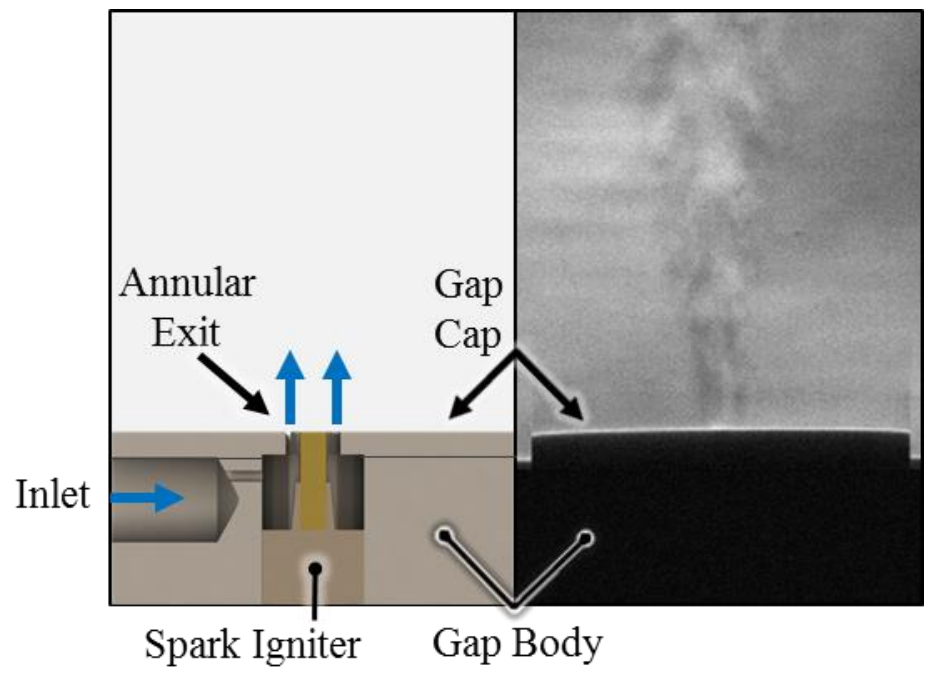

Fig. 3 Juxtaposition of spark igniter cap and schlieren image

The selected dataset contained measurements across ten pressures and six spark gaps with high speed videos were recorded for all combinations. For each set, one background video with flowing gas and no spark discharge was recorded for 1.8 seconds and two data videos were recorded with flowing gas and spark discharges for 1.8 seconds each. The background video was time averaged and subtracted off the raw data videos. Edge detection was performed using a subpixel detection method developed by Trujillo-Pino et al. [9]. Edges were then dilated in the shape of a diamond, and enclosed spaces were filled. The edges of the filled objects remaining were trimmed using a diamond shape resulting in a binarized spatial location of the hot plume of gas. 
AIAA Propulsion and Energy Forum and Exposition (AIAA P\&E 2018);

Duke Energy Convention Center, Cincinnati, OH, 9 - 11 July 2018

An image based trigger was used to determine time zero for each spark discharge. Thirty frames $(3 \mathrm{~ms})$ were collected when the trigger occurred. Frames of the same time stamp were spatially averaged, and a weighted centroid was calculated to compare flow velocities. A second binary processing was performed for completeness. However, centroid locations were less smooth in movement due to multiple objects found per frame, and variation in the object shapes. Velocity calculations of gas movement were within $15 \%$ between the weighted centroid and centroid results on average. An outline of this process is shown in Fig. 4. 
AIAA Propulsion and Energy Forum and Exposition (AIAA P\&E 2018);

Duke Energy Convention Center, Cincinnati, OH, 9 - 11 July 2018

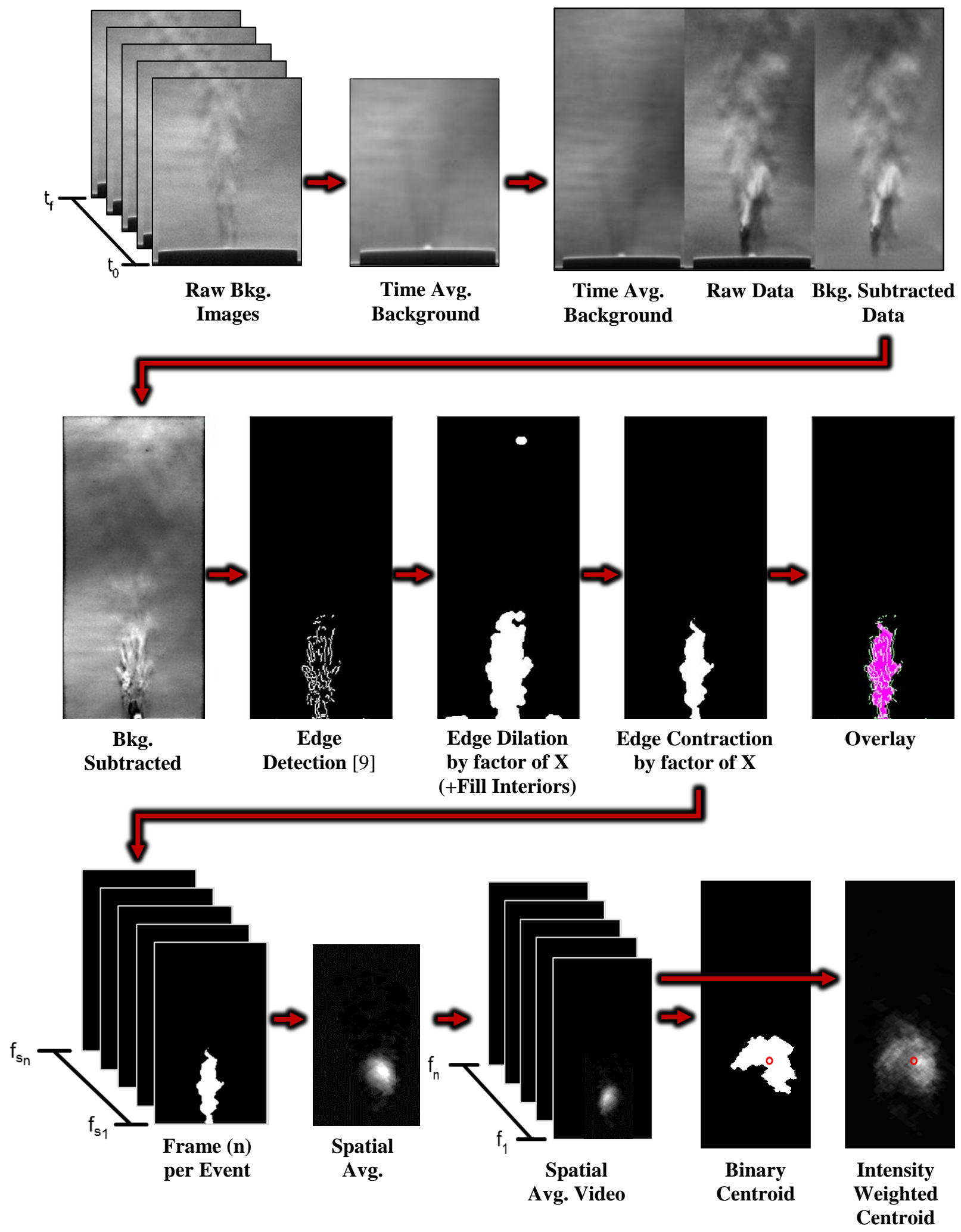

Fig. 4 High Speed Schlieren post-processing methodology 
AIAA Propulsion and Energy Forum and Exposition (AIAA P\&E 2018);

Duke Energy Convention Center, Cincinnati, OH, 9 - 11 July 2018

\section{Results and Discussion}

The most fundamental comparison for spark discharges is Paschen's curve, which shows the relation between breakdown voltage and the pressure-distance product. Paschen's curve is calculated for a uniform electric field between two parallel plate electrodes, in contrast to the annular electrodes in this experiment. It is hypothesized that the electric field is unbalanced as the electric arcs often occurred along a single radial location, rotating to another when the electrodes had eroded or increased resistance via oxidation. Results for the breakdown, shown in Fig. 5, largely trend with Paschen's curve, yet deviate at higher pressure-distance values. This is in agreement with prior work by Ballal using flowing propane-air gas mixtures [2], which implied the cause for deviation is due to the nonuniformity of the electric field. Note that the pressure used is the downstream measurement of venturi, and does not account for losses of the tubing up to the spark gap.

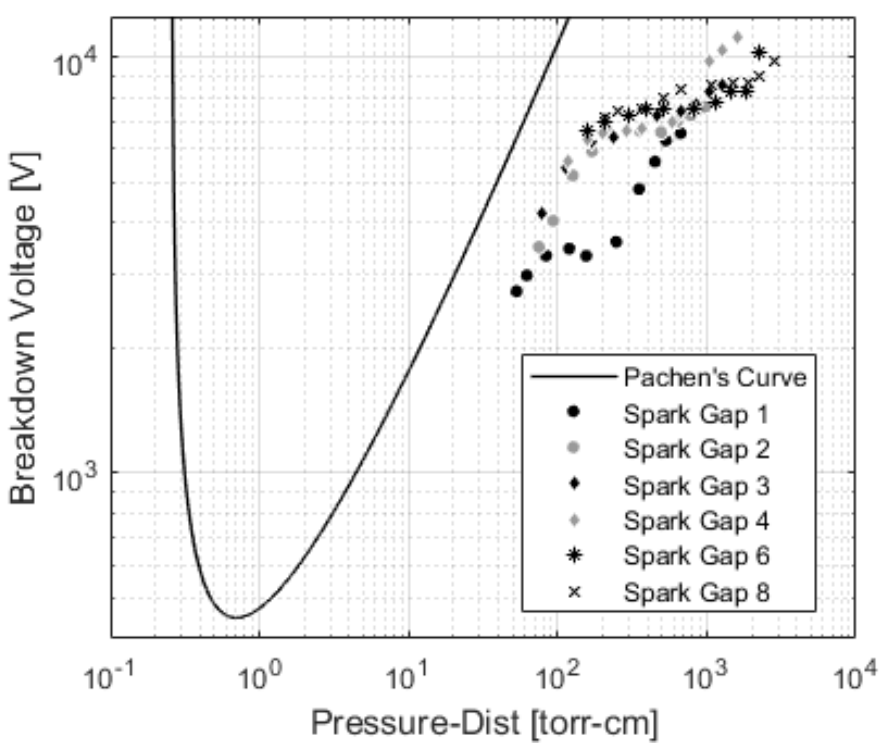

Fig. 5 Breakdown voltage as a function of the pressure-distance product

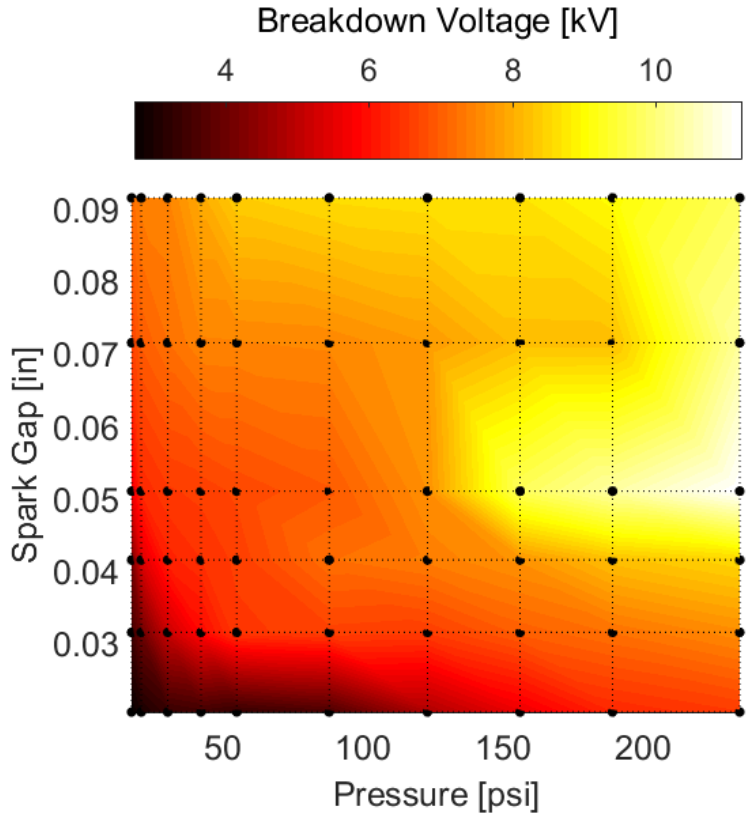

Fig. 6 Surface map of breakdown voltage as a function of pressure and spark-gap distance

The same information is shown as a surface map in Fig. 6 to provide clarity on discrepancies. The strongest deviation was observed for spark gap 1 ( 0.0205 " dia.). The hypothesis of the reduced breakdown voltage is that the electrodes were not oxidized during the first trials, decreasing the resistance against spark formation. The breakdown voltages for remaining tests largely followed expectations.

Spark duration followed a similar pattern to breakdown voltage, which was a less intuitive expectation. In a similar fashion to Fig. 6, a surface map is shown in Fig. 7 with the z-axis being time, and spark duration vs. pressure is shown in Fig. 8. The spark duration clearly increases with pressure, and no clear correlation exists with the spark gap. The product of the pressure-distance, as examined for breakdown shows that spark duration is largely consistent below 200 torr-cm, and rises steadily after shown in Fig. 9. This is the same point where the breakdown voltage changes slope and deviates away from Paschen's curve. 


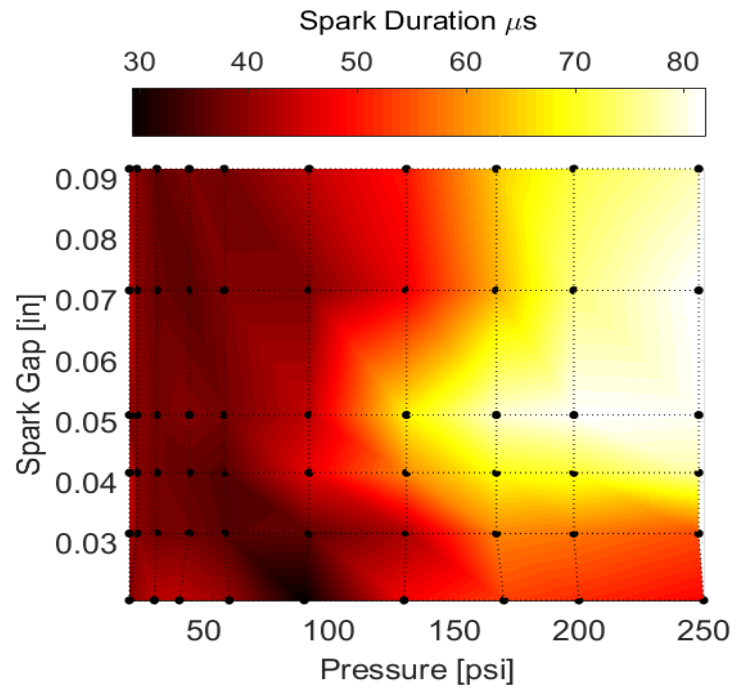

Fig. 7 Surface map of spark duration as a function of pressure and distance

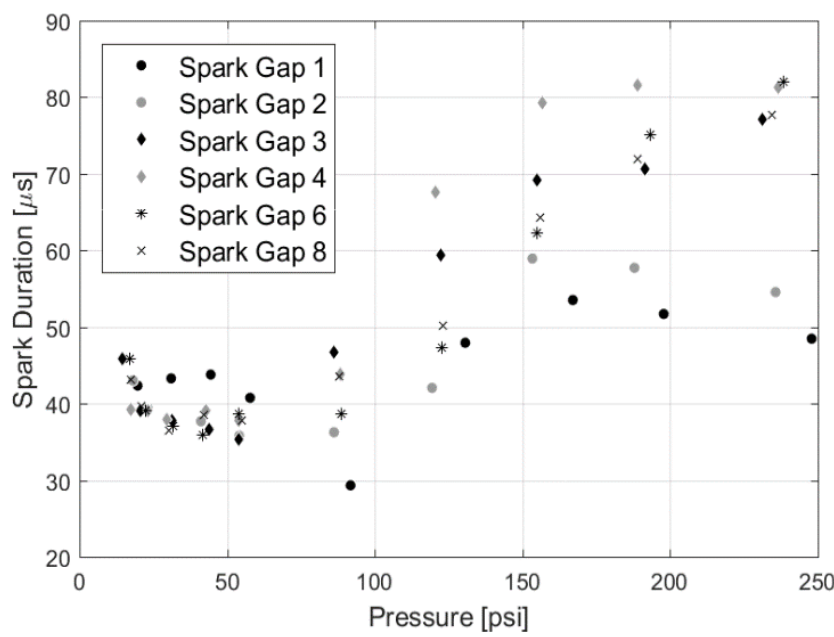

Fig. 8 Spark duration as a function of pressure

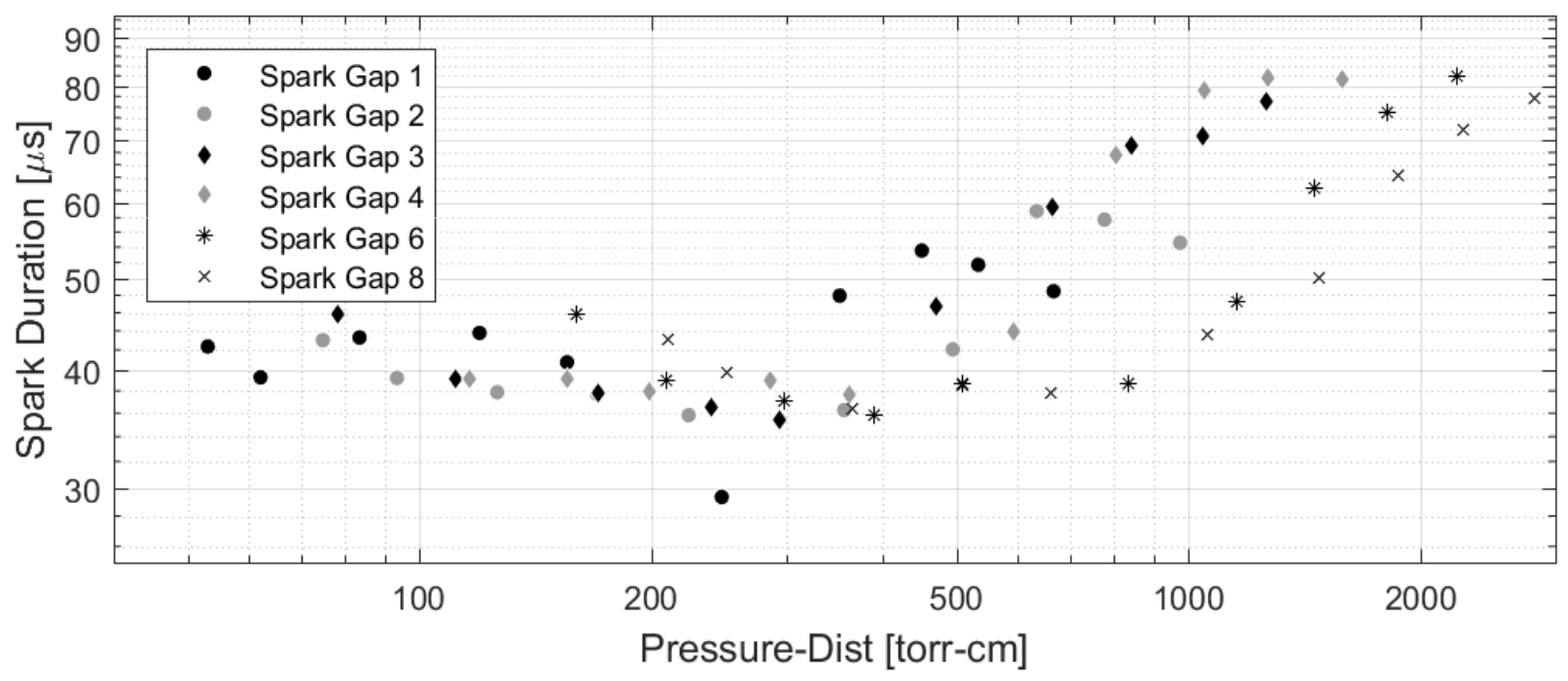

Fig. 9 Spark duration as a function of the pressure-distance product

The instantaneous power was integrated over time to produce the mean energy per measurement at each spark and pressure combination. The mean energy per combination plotted against distance in Fig. 10 shows a minor correlation. Pressure shows a similar, yet minor, trend with energy. Standard deviations of the mean energies show moderately consistent behavior across all spark gaps, with the largest fluctuation at 150 psia. When viewed as a surface, the mean-energy peaks shown in Fig. 11 resemble the spark-duration peaks from Fig. 8. Once again, a trend clearly falls out when using the pressure-distance product as shown in Fig. 12. A power relation is strongly indicated by the linear relation of spark energy and pressure-distance on the log-log plot. Furthermore, the consistency of the mean energies indicate that the breakdown voltage has little effect on mean energy as it was nonlinear and contained outliers from the general trends.

A trend worth noting is the spark energy distribution for each pressure and spark gap. When examining pressures, the majority of cases were bimodal with a primary and secondary peak. 
AIAA Propulsion and Energy Forum and Exposition (AIAA P\&E 2018);

Duke Energy Convention Center, Cincinnati, OH, 9 - 11 July 2018

Secondary peaks were of lower energy for pressures 1-6, and of higher energy for pressures 7-10. At pressure 10, the peaks were virtually equal. When examining spark gaps, the bimodal distribution is well-defined. Spark gap 1 has no dominant mode, and gap 2 has a low energy tail. Spark gaps 3-8 all have high energy tails. Intuitively, the higher energy tails occur at both high pressure and longer distances.

Schlieren imaging was used to calculate the volume of the hot gas plume following the spark discharge. The videos were temporally averaged per time step as outlined in Fig. 4, then binarized a second time to reduce remaining noise. Pixels of each binarized video were summed and normalized to estimate which settings produced the largest volume of hot gas. Low pressures had the highest detection signal with the greatest peaks for larger spark gaps, thus slower flow velocities, as shown in Fig. 15.

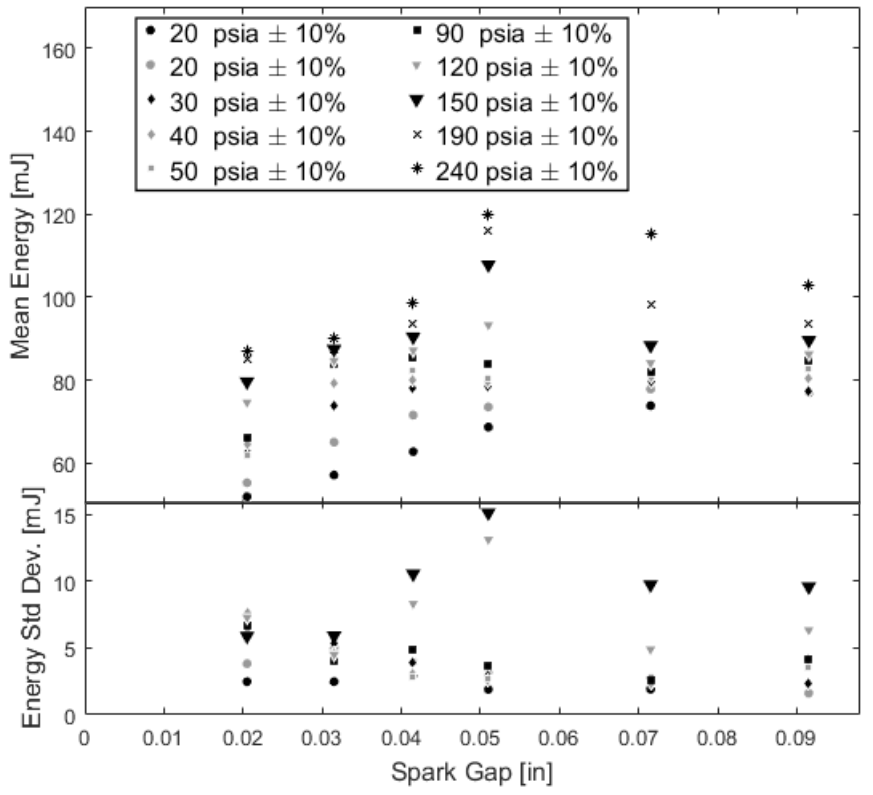

Fig. 10 Mean energy and standard deviation of mean energy as a function of the spark gap distance

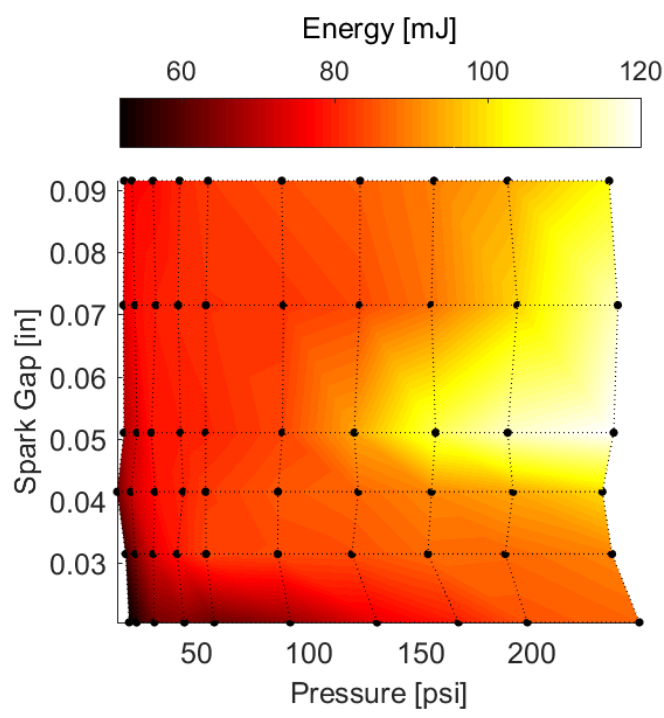

Fig. 11 Surface map of mean energy vs. pressure and spark-gap distance

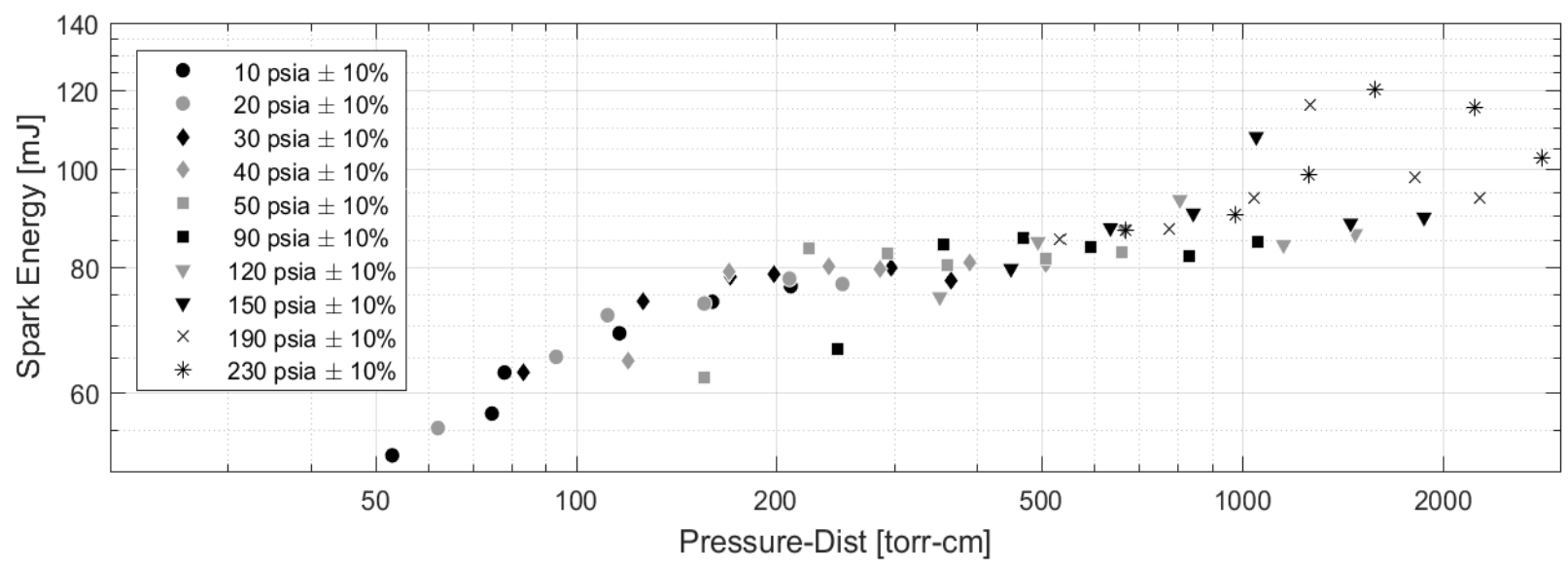

Fig. 12 Mean energy as a function of the pressure-distance product 
AIAA Propulsion and Energy Forum and Exposition (AIAA P\&E 2018);

Duke Energy Convention Center, Cincinnati, OH, 9 - 11 July 2018
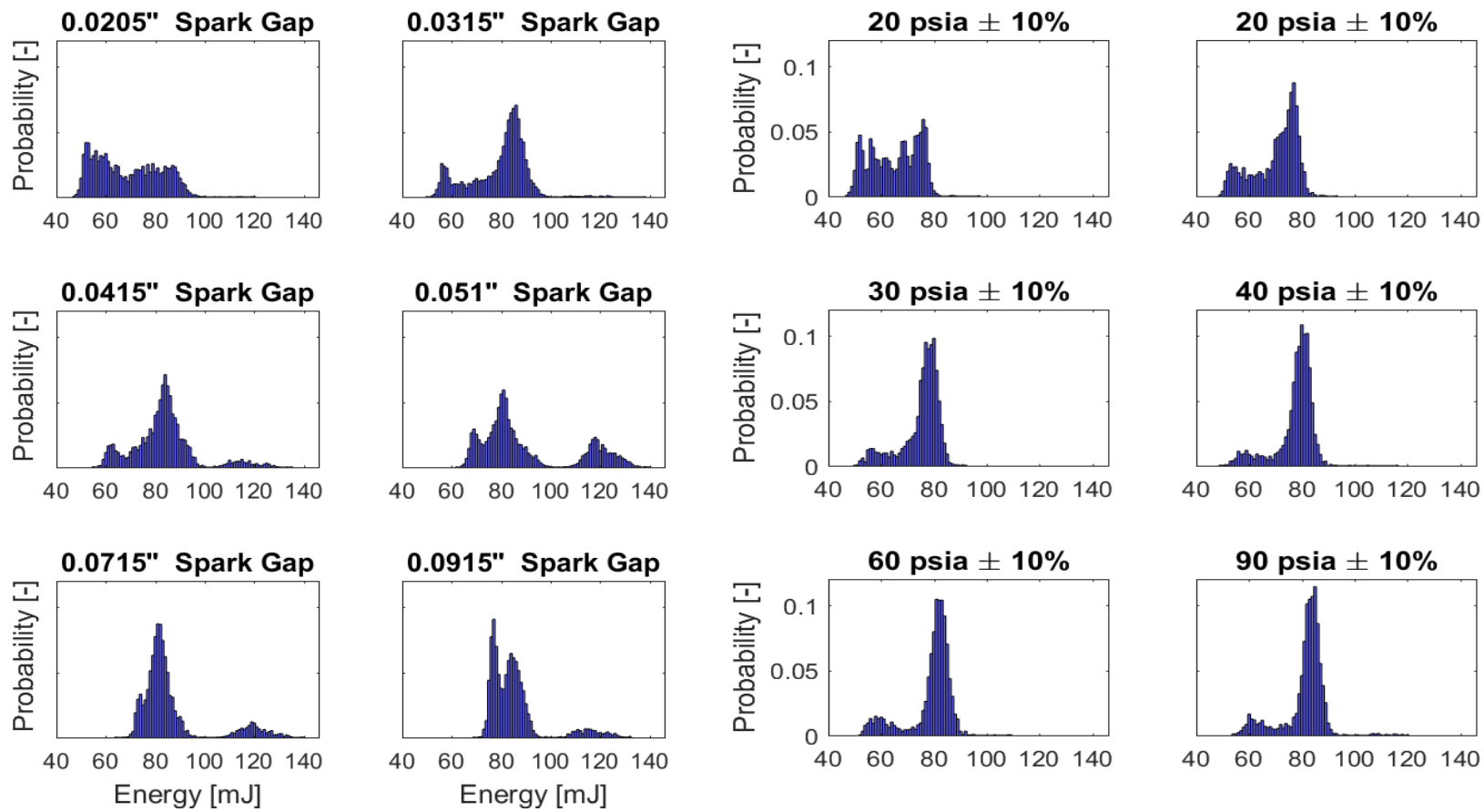

Fig. 13 Probability dist. of mean energy probability per spark gap, each graph contains 4,800 samples

Binarized Volume Sum [a.u.]
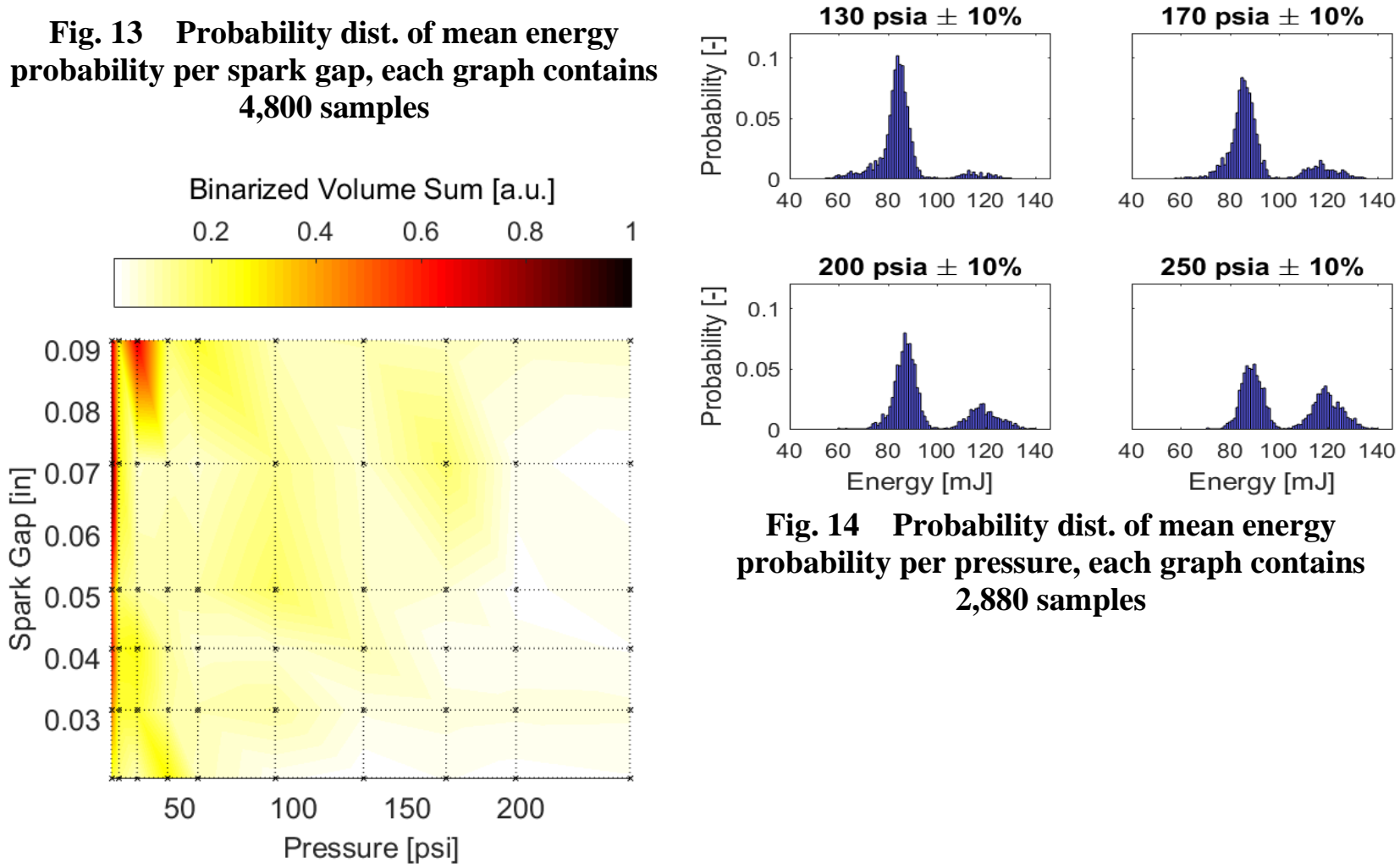

Fig. 14 Probability dist. of mean energy probability per pressure, each graph contains 2,880 samples

Fig. 15 Sum of binarized high speed videos showing hot gas plume following the spark 
AIAA Propulsion and Energy Forum and Exposition (AIAA P\&E 2018);

Duke Energy Convention Center, Cincinnati, OH, 9 - 11 July 2018

\section{Conclusions}

A parametric study of annular spark gaps, pressures, and spark discharges in flowing oxygen gas was performed with a Champion spark exciter. Electrical, fluid property, and Schlieren imaging were recorded for all cases. Schlieren imaging of hot gas plumes following the spark were difficult to process as the exit velocities approached and surpassed sonic velocities. The largest volume of hot gas recorded was for subsonic velocities across all spark gaps, with slower velocities having the longest detection time. The range of the pressure-distance product for the experiment is from approximately 50 torr- $\mathrm{cm}$ to 2500 torr-cm. Measurements of breakdown voltage qualitatively trend with Paschen's curve and results from prior literature [2]. Spark duration remained constant until the pressure-distance product exceeded 200 torr-cm, and then steadily increased. The mean spark energy increases linearly with the pressure-distance on a log-log plot indicating that a definite power relationship exists. The distribution of sparks at low energies and low pressures is not Gaussian and has no dominant peaks. Moderate and high spark energies are bimodal, with the dominant mode near $80 \mathrm{~mJ}$. As pressure increases, dominant and secondary modes approach the same probability.

\section{Acknowledgements}

This work is funded by the NASA Space Technology Research Fellowship.

\section{References}

[1] D. K. Huzel and D. H. Huang, Modern Engineering for Design of Liquid-Propellant Rocket Engines, AIAA, 1992.

[2] D. R. Ballal and A. H. Lefebvre, "The influence of spark dischage characteristics on minimum ignition energy in flowing gases," Combustion and Flame, vol. 24, pp. 99-108, 1975.

[3] T. Yuasa, S. Kadota, M. Tsue, M. Kono, H. Nomura and Y. Ujiie, "Effects of energy deposition schedule on minimum ignition energy in spark ignition of methane/air mixtures," Proceedings of the Combustion Institute, vol. 29, pp. 743-750, 2002.

[4] J. Kleinhenz, C. Sarmiento and W. Marshall, "Spark ignition characteristics of a LO2/LCH4 engine at altitude conditions," in 48th AIAA/ASME/SAE/ASEE Joint Propulsion Conference, Atlanta, 2012.

[5] S. Bane, J. Ziegler and J. Shepherd, "Investigation of the effect of electrode geometry on spark ignition," Combustion and Flame, vol. 162, pp. 462-469, 2015.

[6] N. Kawahara, S. Hashimoto and E. Tomita, "Plasma temperature of spark discharge in a spark-ignition engine using a time series of spectra measurements," in 18th International Symposium on the Application of Laser and Imaging Techniques to Fluid Mechanics, Lisbon, 2016.

[7] C. C. Swett, "Investigation of spark gaps subjected to altitude and air-velocity conditions," National Advisory Committee for Aeronautics, Washington, 1948.

[8] M. Kono, S. Kumagai and T. Sakai, "The optimum condition for ignition of gases by composite sparks," Symposium (International) on Combustion, vol. 16, no. 1, pp. 757-766, 1977.

[9] A. Trujillo-Pino, K. Krissian, M. Aleman-Flores and D. Santana-Cedres, "Accuate subpixel edge location based on partial area effect," Image and Vision Computing, vol. 31, pp. 72-90, 2013. 